$12-2019$

\title{
Selectivity Of Two Commercial Dredges Fished In The Northwest Atlantic Sea Scallop Fishery
}

\section{Sally Roman}

Virginia Institute of Marine Science

David Rudders

Virginia Institute of Marine Science

Follow this and additional works at: https://scholarworks.wm.edu/vimsarticles

Part of the Aquaculture and Fisheries Commons

\section{Recommended Citation}

Roman, Sally and Rudders, David, "Selectivity Of Two Commercial Dredges Fished In The Northwest Atlantic Sea Scallop Fishery" (2019). VIMS Articles. 1818.

https://scholarworks.wm.edu/vimsarticles/1818

This Article is brought to you for free and open access by the Virginia Institute of Marine Science at W\&M ScholarWorks. It has been accepted for inclusion in VIMS Articles by an authorized administrator of W\&M ScholarWorks. For more information, please contact scholarworks@wm.edu. 


\title{
SELECTIVITY OF TWO COMMERCIAL DREDGES FISHED IN THE NORTHWEST ATLANTIC SEA SCALLOP FISHERY
}

\author{
SALLY A. ROMAN* AND DAVID B. RUDDERS \\ Virginia Institute of Marine Science, William \& Mary, PO Box 1346, Gloucester Point, VA 23062
}

\begin{abstract}
Size selectivity curves were estimated for two commercial dredge configurations used in the United States Atlantic sea scallop (Placopecten magellanicus) fishery. Traditionally, the New Bedford Style dredge (New Bedford dredge) has been used by the commercial fleet; however, since 2013, the Coonamessett Farm Turtle Deflector Dredge (turtle dredge) has been required seasonally in the Mid-Atlantic region to minimize the capture of sea turtles. This analysis provides estimates of selectivity and relative efficiency for the turtle dredge and the New Bedford dredge. Selectivity information for the turtle dredge is currently unknown, and selectivity for the New Bedford dredge was originally assessed in 2008. The Share Each Length's Catch Total method was used to model scallop catch-at-length data for each commercial dredge with data collected during the Virginia Institute of Marine Science fishery-independent surveys in 2015 to 2017, conducted onboard commercial fishing vessels. The surveys were conducted in the Mid-Atlantic and Georges Bank regions of the resource in three distinct areas. A paired study design was used, where a nonselective National Marine Fisheries Service sea scallop survey dredge and either the turtle dredge or New Bedford dredge were towed simultaneously at each survey station. To assess for time-varying changes in selectivity, results were compared with the 2008 New Bedford dredge analysis. Results indicated the 50\% retention length was $98.2 \mathrm{~mm}$, with a selection range of $28.2 \mathrm{~mm}$ and a relative efficiency of 0.83 for the turtle dredge. New Bedford dredge results estimated a $50 \%$ retention length of $107.4 \mathrm{~mm}$, selection range of $50.5 \mathrm{~mm}$ and relative efficiency of 0.81 . Comparing selectivity profiles for the turtle dredge and New Bedford dredge with the 2008 results indicated a shift toward increased retention probability for smaller size classes of scallops.
\end{abstract}

KEY WORDS: selectivity, Placopecten magellanicus, sea scallop dredge fishery, New Bedford style dredge, Coonamessett Turtle Deflector Dredge, SELECT

\section{INTRODUCTION}

Understanding the selective profile of fishing gear is a critical aspect of fisheries management and stock assessments. Selectivity is defined as the proportion of a population that is captured when encountered using fishing gear and provides a probabilistic framework for a fish at a given size being retained by the commercial gear (Millar 1992, Millar et al. 2004, Yochum \& DuPaul 2008, Cadrin et al. 2016). Modifying selectivity through changes to fishing gear decreases the catch of juvenile fish, improves exploitation patterns, and can increase future yield by limiting growth overfishing while allowing fish to reach maturity (Kvamme \& Frøysa 2004, Millar et al. 2004, Stepputtis et al. 2016). Estimation of the selective profile of a gear can inform the development of management measure ranging from minimum landing sizes to gear regulations to minimize the catch of juveniles or undesired size classes (Revill \& Holst 2004, Stepputtis et al. 2016). Selectivity is also used for estimating the sources of mortality, i.e., fishing and incidental, development of length frequencies, and is used in fully integrated assessment models (Millar \& Fryer 1999, Yochum \& DuPaul 2008, Cadrin et al. 2016). The treatment of selectivity in assessment models can vary. Selectivity can be time invariant, time varying, or estimated within a model, and several studies have demonstrated the sensitivity of assessment results to changes in selectivity and underlying assumptions regarding this parameter (Linton \& Bence 2011, Nielsen \& Berg 2014, Cadrin et al. 2016). Understanding if selectivity for a commercial gear has changed over time, as a result of changes in fishing technology or practices, can help

*Corresponding author. E-mail: saroman@vims.edu DOI: $10.2983 / 035.038 .0308$ support the specification of commercial gear selectivity in the assessment process.

The U.S. Atlantic sea scallop (Placopecten magellanicus) fishery is prosecuted from the Mid-Atlantic Bight to Georges Bank in the northwest Atlantic Ocean (NEFSC 2018). The fishery is managed through a combination of input and output controls, with the overarching goal of minimizing the impact on small scallops in an effort to maximize yield per recruit, minimize discarding, and increase reproductive output (NEFMC 2003). Input controls consist of effort restrictions (maximum annual days-at-sea), crew size limitations, and gear regulations. Harvest quotas within a spatial area management framework are used as an output control.

Most sea scallops are harvested commercially with either a New Bedford style (New Bedford dredge) or a Coonamessett Farm Turtle Deflector Dredge (turtle dredge). The New Bedford dredge has traditionally been used in the fishery and was the only regulated gear permitted until 2013 (NEFMC 2011). More recently, the turtle dredge was designed to minimize the capture of sea turtles by modifying the New Bedford dredge frame (Smolowitz et al. 2012a) (Fig. 1). The gear was regulated for use in the fishery beginning in 2013 (NEFMC 2011, Smolowitz et al. 2012a). Regulations require the seasonal use (May 1-November 30) of the turtle dredge in the Mid-Atlantic Bight west of $71^{\circ} \mathrm{W}$ longitude (NEFMC 2018). Commercial fishers harvest scallops using the turtle dredge beyond the seasonal requirement in the Mid-Atlantic Bight and on Georges Bank, according to data provided by the Greater Atlantic Regional Fisheries Office of the National Oceanic and Atmospheric Administration.

In 2003, gear regulations were adopted to change the selectivity of the New Bedford dredge to reduce the catch of small scallops to meet management objectives. The minimum ring size was enlarged from 89 to $102 \mathrm{~mm}$ and the twine top stretched mesh size was 
New Bedford Style Dredge
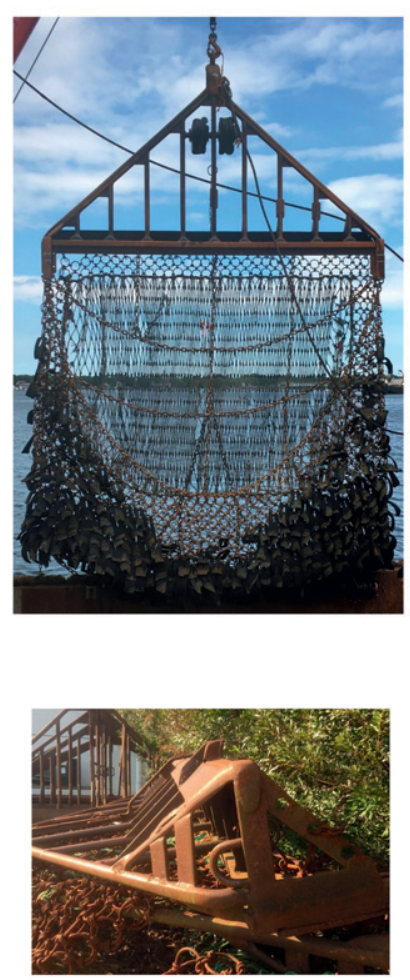

Coonamessett Farm Turtle Deflector Dredge
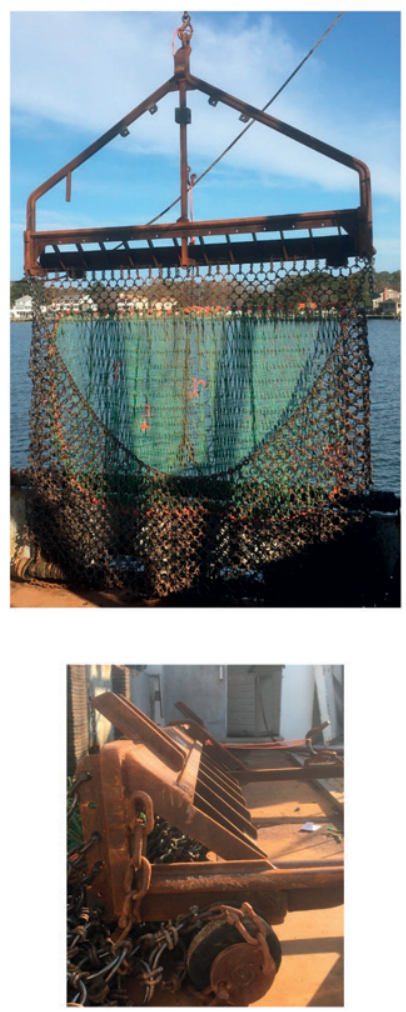

Figure 1. New Bedford style commercial scallop dredge (left) and Coonamessett Farm Turtle Deflector Dredge (turtle dredge) (right). Top pictures provide an overall view of each dredge frame. Bottom pictures are side views of the dredge frames.

required to be a minimum of $254 \mathrm{~mm}$ (NEFMC 2003). The effect of these regulations on New Bedford dredge selectivity was evaluated by Yochum and DuPaul (2008). The study found the New Bedford dredge retained $50 \%$ of scallops at $100.1 \mathrm{~mm}$ in length, which satisfied the management objectives of reducing the catch of undersized scallops while increasing the future yield per recruit. The study also estimated the relative efficiency of the New Bedford dredge compared with a National Marine Fisheries Service (NMFS) survey dredge, used since 1979 to survey the sea scallop resource (NEFSC 2018). The relative efficiency estimate of 0.77 was greater than the assumed value of 0.65 .

The turtle dredge has been in use since 2013, but a selectivity analysis has not been completed to understand the selective profile of the gear or relative efficiency compared with the NMFS survey dredge. The turtle dredge has similar regulations regarding minimum ring size and twine top sizes as the New Bedford dredge, indicating that selectivity estimates should be comparable. Although, communications with commercial fishers indicate different operating procedures for this dredge, specifically towing speed and the scope to depth ratio, relative to the New Bedford dredge. These differences, along with the modification in the dredge frame design, may have an impact on the contact selectivity of the gear.

The objectives of this article were to assess the selectivity of two commercial dredges, the turtle dredge and New Bedford dredge, generate selectivity curves, and provide estimates of

relative efficiency, compared with the NMFS survey dredge for both dredges. To investigate changes in selectivity over time, selectivity estimates derived from this study are compared with those calculated by Yochum and DuPaul (2008).

\section{MATERIALS AND METHODS}

\section{Data Collection}

Comparative catch data were collected during the Virginia Institute of Marine Science fishery-independent sea scallop dredge surveys in 2015, 2016, and 2017 conducted onboard commercial fishing vessels chartered as research platforms. The Mid-Atlantic Bight resource area was surveyed annually during the month of May from 2015 through 2017 (Fig. 2). Five vessels participated in the survey over the 3-y period. Separate surveys of two distinct areas in the Georges Bank region, Nantucket Lightship (NLCA) and Closed Area II (CAII), were conducted in 2016 and 2017 in June and July, respectively,(Fig. 2). One vessel was used to survey the NLCA in both years, whereas two different vessels were used to conduct the CAII survey each year. All areas surveyed have similar sand substrate, and dredge performance for both the survey and commercial dredges are assumed to be consistent (NEFSC 2018).

A paired study design was used, where a vessel towed a NMFS survey dredge and either a turtle dredge or New Bedford dredge at each survey station. For all Mid-Atlantic Bight surveys, the turtle dredge was used, and for the NLCA and CAII surveys conducted on Georges Bank, a New Bedford dredge was fished. The turtle dredge was used during the Mid-Atlantic Bight surveys to comply with regulations. The NMFS dredge had a 2.4-m wide frame equipped with 5.1-cm rings, 10.2-cm diamond twine top, and a 3.8$\mathrm{cm}$ diamond mesh liner. The NMFS survey dredge is assumed to be nonselective for scallops greater than $40 \mathrm{~mm}$ because of the use of the mesh liner inside the dredge (NEFSC 2018). Commercial dredge specifications varied between vessels; all dredges met the current gear regulations. The vessel participating in the CAII survey in 2016 had a 4.6- $\mathrm{m}$ wide dredge, whereas all other vessels used a 4.3-m wide commercial dredge. Other commercial gear characteristics, including twine top hanging ratio, twine top dimensions, and dredge bag dimensions, also differed between vessels. This variability allowed us to capture the gear variability present in the commercial fishery, similar to the study by Yochum and DuPaul (2008). Survey tows followed standard protocols, with a 15-min tow time at a speed over ground of approximately 6.1-6.4 km per hour (kph) and a 3:1 scope to depth ratio (e.g., for a depth of $25 \mathrm{~m}, 75 \mathrm{~m}$ of wire was set).

All scallop catches from each dredge were kept separate and placed into baskets to quantify the total catch. To calculate the number and length distribution of scallops caught at each station, either the total scallop catch or a subsample, depending on catch volume, was measured to the nearest mm (total length). Catch-at-length for the entire catch (i.e., expanded catch) at a station was determined by applying an expansion factor ( $\left.\frac{\text { number of baskets caught }}{\text { number of baskets measured }}\right)$ to the sampled number caught-at-length (DuPaul \& Kirkley 1995, Yochum \& DuPaul 2008).

\section{Selectivity}

Five selectivity analyses were conducted: turtle dredge, NLCA, CAII 2016, CAII 2017, and a pooled New Bedford dredge. The turtle dredge analysis included data from all MidAtlantic Bight surveys. Nantucket Lightship survey data were 


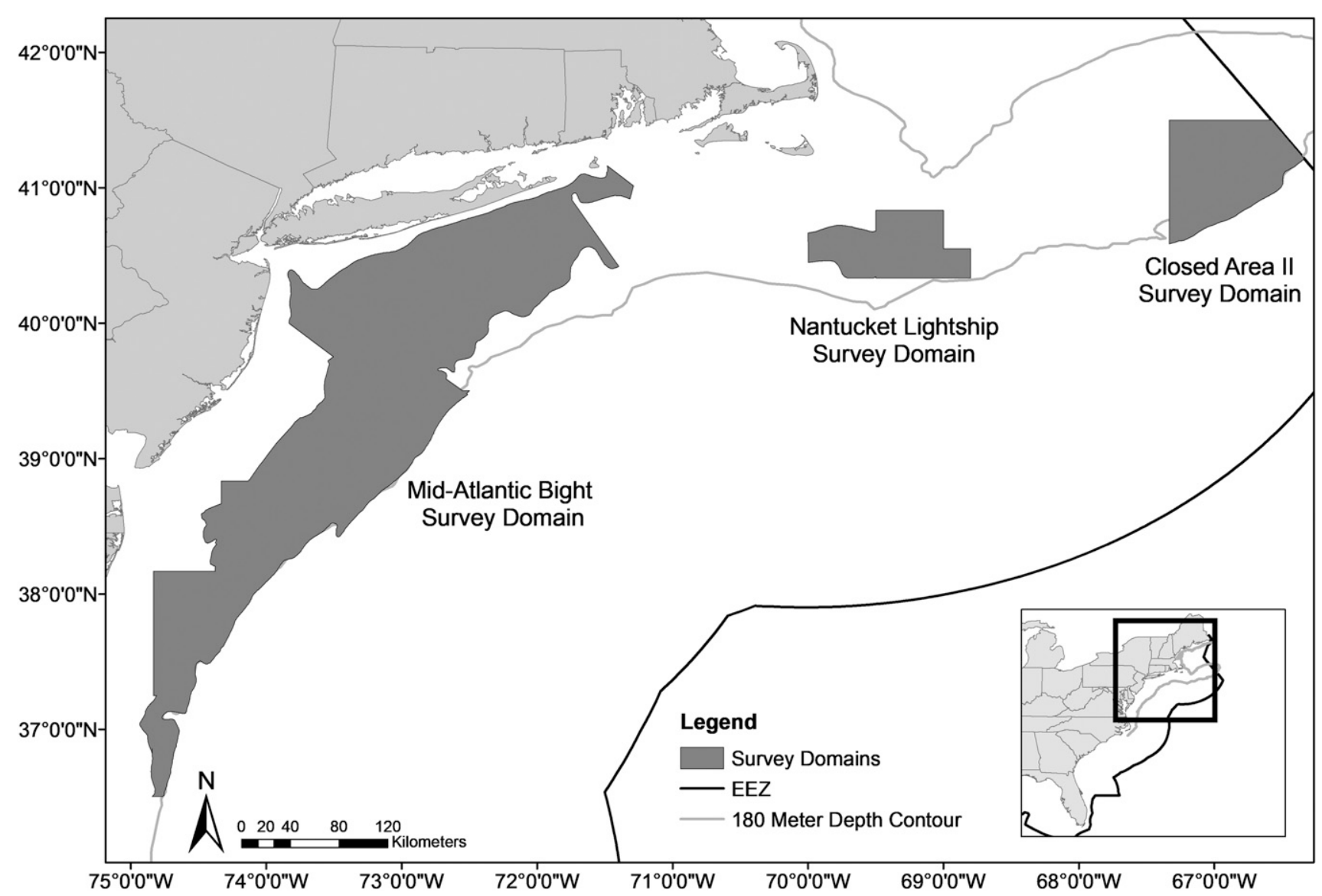

Figure 2. Map showing the Virginia Institute of Marine Science survey domains for the Mid-Atlantic Bight, NLCA, and CAII surveys for 2015 to 2017, along with the Economic Exclusive Zone (EEZ) and 180-m depth contour. The NLCA and CAII surveys are in the Georges Bank subunit, and the MidAtlantic Bight survey is in the Mid-Atlantic subunit of the resource.

examined separately from the CAII survey data to determine if data from these two surveys could be combined for a pooled New Bedford dredge analysis. Separate analyses were completed for the 2016 and 2017 CAII surveys to estimate relative efficiency due to differences in the commercial dredge width between years. For the pooled New Bedford dredge analysis, data from the NLCA and CAII surveys were combined after individual analysis confirmed this approach was appropriate. Selectivity curves for the turtle dredge and the New Bedford dredge were compared to assess for differences in the selective profiles of both gears.

Any tow deemed to be invalid (i.e., tow was classified as fouled for the survey dredge) was excluded. Invalid tows could result from the survey dredge flipping over or the dredge having other issues that would make it fish incorrectly. The expanded number of scallops-at-length, as described earlier, was used for all analyses. Any pair with no scallop catch or less than 20 scallops captured in either dredge was omitted. Catch-at-length for the remaining tow pairs was binned into $5 \mathrm{~mm}$ length bins. Plots of the ratio of catch-at-length caught in the commercial dredge to the total catch-at-length in both dredges $\left(\frac{\text { commercial catch }}{\text { commercial + survey catch }}\right)$ were examined to assess data quality.

Selectivity was analyzed with the Share Each Length's Catch Total (SELECT) method developed by Millar (1992). This is one of the preferred techniques for estimating selectivity curves for a multitude of gear types, including scallop dredges (Millar 1992, Yochum \& DuPaul 2008, Park et al. 2011, Smith et al. 2017, NEFSC 2018). The SELECT method was used to estimate selectivity parameter estimates, size selectivity curves, and relative efficiency values for both commercial gears (Millar 1992, Millar \& Fryer 1999). This analytical approach conditions the catch of the selective gear at length $l$ to the total catch from both gears (i.e., commercial and nonselective survey gear) as follows:

$$
\Phi_{c}(l)=\frac{p_{c} r_{c}(l)}{p_{c} r_{c}+\left(1-p_{c}\right)},
$$

where $\Phi_{c}(l)$ is the proportion of scallops-at-length caught in the commercial gear compared with the total catch in both gears, $r_{c}(l)$ is the probability of a fish at length $l$ being retained by the commercial gear given contact, and $p_{c}$ is the split parameter and is the measure of relative efficiency for the commercial gear (Millar 1992). The split parameter $p_{c}$ can be assumed and held at a constant value based on the ratio of the widths for two gears in the selectivity study $\left(\frac{\text { commercial dredge width }}{\text { commercial dredge width }+ \text { survey dredge width }}\right)$ or be estimated within the model (Park et al. 2007). Two models were developed, one with an assumed $p_{c}$ and one which allowed the model to estimate this parameter. This allowed for an assessment of 
the differences between the assumed and estimated $p_{c}$ for each commercial gear, as well as to compare relative efficiency between the two commercial gear types. The assumed $p_{c}$ values were 0.64 for a $4.3-\mathrm{m}$ commercial dredge and 0.65 for a 4.6-m dredge. Model fits were assessed with the Akaike Information Criterion (AIC) and examination of deviance residuals.

Yochum and DuPaul (2008) found the logistic function provided the best fit to scallop dredge data. The logistic function is also the most common functional form observed for towed fishing gear selectivity studies (Millar 1992, Park et al. 2011). Both the logistic and Richards models were fit to the scallop dredge data to assess the relative fit of different functional forms. Model fits were evaluated with AIC and residual diagnostics. The logistic selection curve is defined as follows:

$$
r_{c}(l)=\frac{\exp (a+b l)}{1+\exp (a+b l)},
$$

where $r_{c}(l)$ is defined as in Eq. 1 and $a$ and $b$ are the logistic selection curve parameters, the intercept and slope, respectively. Substituting Eq. 2 into Eq. 1 for $r_{c}(l)$ results in modeling selectivity with the SELECT method and the logistic functional form as follows:

$$
\Phi_{c}(l)=\frac{p_{c} \exp (a+b l)}{\left(1-p_{c}\right)+\exp (a+b l)},
$$

where are all parameters retain their definitions from Eqs. 1 and 2. Models were fit using a maximum likelihood approach (Millar 1992). Parameter estimates for $a$ and $b$ allow for the calculation of $l_{50}=-a / b$ and $S R=\left[2 \log _{e}(3)\right] / b$, (Millar \& Fryer 1999) where $l_{50}$ is the length at which $50 \%$ of animals have the probability of being retained and $S R$ is the selection range, the difference between 25 th and 75 th percent retention probability at size. Both $l_{50}$ and $S R$ values are used to describe and assess gear selectivity across fisheries and gears worldwide (Millar \& Fryer 1999, Stepputtis et al. 2016). Predicted selectivity curves for both dredges were estimated with the selectivity parameters $\left(a, b\right.$, and $\left.p_{c}\right)$ from the preferred models.

Between-haul variability can exist for paired field studies because of replicate tows and variability in environmental factors, which can lead to overdispersion. Potential overdispersion was addressed by calculating a replication estimate of betweenhaul variation (REP factor) (Millar et al. 2004). The REP factor is calculated as the Pearson chi-squared statistic for model goodness of fit divided by the degrees of freedom. The REP factor corrects SE of parameter estimates by multiplying the SE

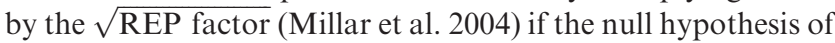
no extra variation in the data is rejected. All analyses were completed with the $\mathrm{R}$ statistical software and the trawlfunctions package (R Core Team 2016). The trawlfunctions package documentation and code can be found at http://www.stat. auckland.ac.nz/ millar/selectware/code.html.

\section{RESULTS}

\section{Data Characteristics}

A total of 1,207 successful tow pairs were completed across the three surveys onboard eight commercial vessels. The turtle dredge analysis had the greatest number of pairs, 982. The
NLCA and CAII surveys each had approximately 100 pairs, and the sample size for the New Bedford dredge was 235 (Table 1). The number of pairs between years and across gears was consistent.

\section{SELECT Model Selection}

The logistic selectivity curve had a better fit across all models, with lower AIC values compared with the Richards models and superior residual diagnostics. Richards models also failed to converge for several models. Logistic models that estimated $p_{c}$ also had lower AIC values and a better fit compared with the assumed $p_{c}$ models with the same functional form. All models were overdispersed, and SE for parameter estimates was corrected for by multiplying the SE by the $\sqrt{\text { REP factor }}$ (Millar et al. 2004).

For all models, the observed and predicted selectivity curves compared relatively well, and deviance residuals indicated model fits were satisfactory (Fig. 3). At smaller and larger size classes, there were length intervals, where the modeled proportion-at-length deviated from the observed values. The largest differences between the observed and predicted values were seen in the turtle dredge and CAII 2017 analyses (Fig. 3). This is a result of the number of animals captured at a given size, where at either tail of the length distribution, few scallops were caught in either dredge and the frequency of occurrence was reduced. The deviance residuals exhibit some patterns as a result of this issue.

\section{Turtle Dredge}

The turtle dredge $l_{50}$ estimate was $98.2 \mathrm{~mm}$, with an $S R$ of $28.2 \mathrm{~mm}$ and relative efficiency of 0.83 (Table 1 ). The $l_{50}$ value is the smallest estimate from all analyses, whereas the relative efficiency value was the greatest estimate. The turtle dredge selectivity curve indicates the dredge has a high probability of retaining smaller scallops, as illustrated by the low $l_{50}$ value (Fig. 4).

\section{New Bedford Dredge}

The CAII surveys had the largest $l_{50}$ estimates of $110.7 \mathrm{~mm}$ and $108.2 \mathrm{~mm}$, whereas the NLCA value was slightly lower at $104.3 \mathrm{~mm}$ (Table 1). $S R$ values ranged from $19.4 \mathrm{~mm}$ for the CAII 2016 survey to $47 \mathrm{~mm}$ for the NLCA survey (Table 1). Relative efficiency estimates for the three surveys were consistent, with values from $0.77-0.81$ (Table 1). This result indicates commercial dredge width did not impact the relative efficiency of the commercial gear. Relative efficiency and $l_{50}$ estimates were similar for all three surveys when including $95 \%$ confidence intervals (CI) (Fig. 5). The only difference was for the $S R$ values, where both CAII surveys had smaller ranges compared with the NLCA survey (Table 1). These findings indicate data from all three surveys could be combined to estimate a pooled selectivity curve for the gear that is a representative of different resource conditions and gear characteristics.

Pooled New Bedford dredge results indicate the $l_{50}$ was $107.4 \mathrm{~mm}, S R$ was $50.5 \mathrm{~mm}$, and estimated relative efficiency was 0.81 . The selectivity curve shows the gear has a higher probability of retention for smaller sizes and a decline in the retention probability at the largest size classes. The retention probability does not equal one for the largest size classes (Fig. 4). 
TABLE 1.

Estimates from the logistic SELECT models for the different surveys and commercial gears.

\begin{tabular}{|c|c|c|c|c|c|c|c|c|c|c|}
\hline Survey/area & Dredge & $a$ & $b$ & $p_{c}$ & $l_{25}(\mathrm{~mm})$ & $l_{50}(\mathrm{~mm})$ & $l_{75}(\mathrm{~mm})$ & $S R(\mathrm{~mm})$ & REP factor & Number of tows \\
\hline Mid-Atlantic & Turtle & -7.65 & 0.08 & $0.83(0.003)$ & $84.1(0.5)$ & $98.2(0.6)$ & $112.3(0.7)$ & $28.2(0.3)$ & 18.10 & 982 \\
\hline NLCA & $\begin{array}{c}\text { New } \\
\text { Bedford }\end{array}$ & -4.87 & 0.05 & $0.81(0.02)$ & $80.8(3.8)$ & $104.3(8.0)$ & $127.7(6.0)$ & $47.0(2.5)$ & 49.97 & 113 \\
\hline CAII 2016 & $\begin{array}{c}\text { New } \\
\text { Bedford }\end{array}$ & -12.52 & 0.11 & $0.77(0.02)$ & $100.9(1.0)$ & $110.7(1.3)$ & $120.4(1.7)$ & $19.4(0.8)$ & 6.96 & 54 \\
\hline CAII 2017 & $\begin{array}{c}\text { New } \\
\text { Bedford }\end{array}$ & -8.92 & 0.08 & $0.79(0.01)$ & $94.2(1.6)$ & $108.2(2.2)$ & $121.6(2.9)$ & $26.7(1.5)$ & 8.15 & 58 \\
\hline Georges Bank & $\begin{array}{c}\text { New } \\
\text { Bedford }\end{array}$ & -4.67 & 0.04 & $0.81(0.01)$ & $82.1(3.0)$ & $107.4(3.9)$ & $132.6(4.9)$ & $50.5(2.0)$ & 30.52 & 225 \\
\hline Yochum and DuPaul (2008) & $\begin{array}{c}\text { New } \\
\text { Bedford }\end{array}$ & -9.32 & 0.09 & $0.77(0.004)$ & - & $100.1(0.6)$ & - & $23.6(0.6)$ & 7.98 & 173 \\
\hline
\end{tabular}

Rows in bold indicate commercial gear parameter estimates for the Coonamessett Farm Turtle Deflector Dredge (turtle dredge) and New Bedford dredge for this study. Estimates from the Yochum and DuPaul (2008) study are provided in the last row for comparison. Model parameter estimates for the intercept $(a)$, slope $(b)$, and relative efficiency $\left(p_{c}\right)$ are provided, as well as the 25 th percent $\left(l_{25}\right)$, 50th percent $\left(l_{50}\right)$, and 75 th percent $\left(l_{75}\right)$ retention probabilities, and the $S R\left(l_{75}-l_{25}\right)$. The replication estimate of between-haul variation (REP factor) and number of valid tow pairs used in each analysis is provided in the last two columns. For $p_{c}, l_{25}, l_{50}, l_{75}$, and $S R$, SE are included in parentheses and corrected for with REP factor $(\mathrm{SE} \cdot \sqrt{\mathrm{REP}})$.

\section{Turtle Dredge versus New Bedford Dredge Comparison}

The turtle dredge $l_{50}$ estimate of $98.2 \mathrm{~mm}$ was significantly lower than the New Bedford dredge value $107.4 \mathrm{~mm}$ (Fig. 6). The difference between the upper CI for the turtle dredge and the lower CI for the New Bedford dredge is 0.4. The gears also differed in the $S R$; the New Bedford dredge $S R$ was wider than the turtle dredge $S R$ (Table 1). Relative efficiency estimates for both gears were similar and indicated both dredges were more efficient than expectation (Fig. 6). Examination of the selectivity curves showed the turtle dredge had a higher probability of retaining larger size classes compared with the New Bedford Dredge, whereas the New Bedford dredge had the ability to catch a wider range of scallop sizes, especially smaller size classes (Fig. 4).

\section{DISCUSSION}

Results indicate the turtle dredge selective profile deviates from the New Bedford dredge results presented in this article, as well as the 2008 findings of Yochum and DuPaul for the New Bedford dredge. The $l_{50}$ and $S R$ values are reduced for the turtle dredge compared with the New Bedford dredge estimates from this study, and there is a significant difference between $l_{50}$ estimates. The gear has a greater relative efficiency in relation to the NMFS survey dredge, a lower $l_{50}$ value, and a $S R$ that is shifted to select for smaller scallops in contrast to the 2008 New Bedford dredge estimates.

Although this analysis is a representative of the turtle dredge in the Mid-Atlantic Bight, the use of this gear throughout the range of the scallop resource has expanded since being required in 2013. The turtle dredge is fished in the Mid-Atlantic Bight region throughout the year and also on Georges Bank, according to data provided by the Greater Atlantic Regional Fisheries Office of National Oceanic and Atmospheric Administration. In the Mid-Atlantic region, year-round use has increased from 58\% in 2013 to 79 and $77 \%$ in 2016 and 2017, respectively. The commercial fleet also fishes with this gear on Georges Bank in the absence of regulation. Usage has grown from $14 \%$ to $38 \%$ from 2013 through 2017. Anecdotal comments from commercial fishers indicate a preference for using the turtle dredge across the resource because the turtle dredge is viewed as catching less bycatch and debris. Yochum and DuPaul (2008) combined data for the New Bedford dredge from both the Mid-Atlantic and Georges Bank regions for their analysis, after finding the results from different cruises and areas were similar. Whereas no regional differences were observed in 2008, resource and fishing practices have changed since the study was conducted. Although there were no significant differences between the NLCA and CAII selectivity parameters in this study, indicating the two Georges Bank areas could be combined, the selective profile of the New Bedford dredge appears to differ between the two Georges Bank areas. Understanding the effects of the turtle dredge on Georges Bank will provide additional information on how the fishery operates under current management and resource conditions. Further studies to estimate the selective profile of the turtle dredge across the entire sea scallop resource should be conducted to determine if spatial variability in the selective profile exists for the turtle dredge.

The lower $l_{50}$ value of the turtle dredge, compared with the New Bedford dredge findings from this study and the 2008 New Bedford dredge results, is an indication the turtle dredge has the potential to catch smaller scallops. Smolowitz et al. (2012b) found that the turtle dredge caught a greater number of small scallops compared with the New Bedford dredge. Differences in selectivity between the two commercial gear types may lead to increased catches of smaller scallops when using the turtle dredge, resulting in discarding in the fishery. The fishery does not generally retain scallops less than $90 \mathrm{~mm}$, as scallops are discarded as a result of market demands or high grading (NEFSC 2018). Evidence of this effect may exist, as discards in the Mid-Atlantic region increased in 2016 and 2017 (NEFSC 2018). This is the 


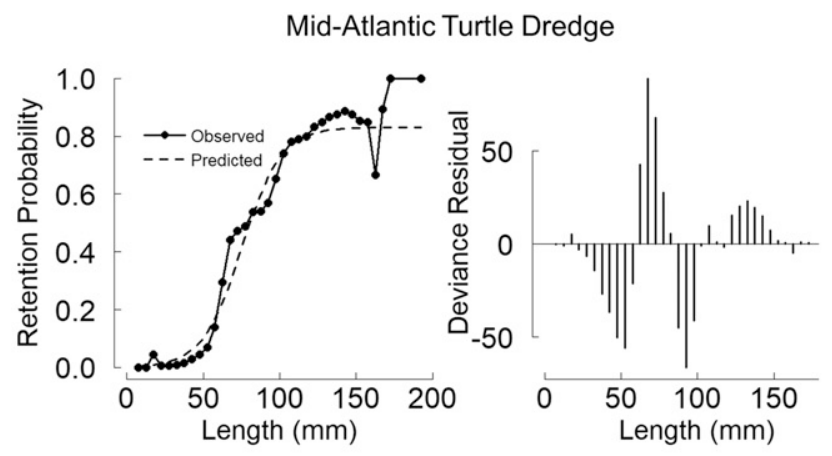

CAll 2016 New Bedford Dredge
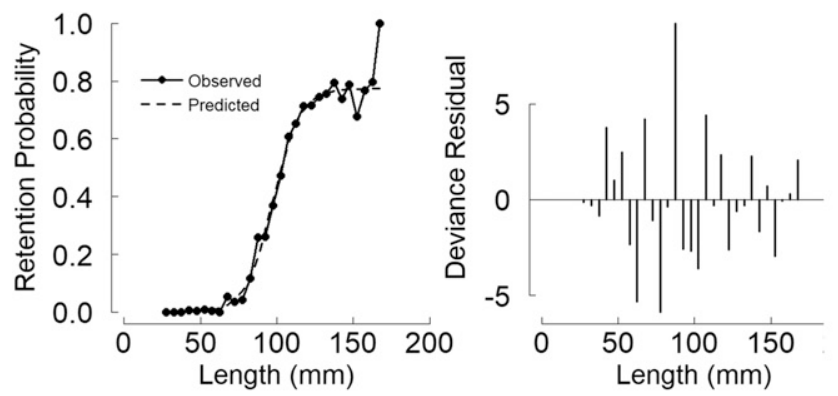

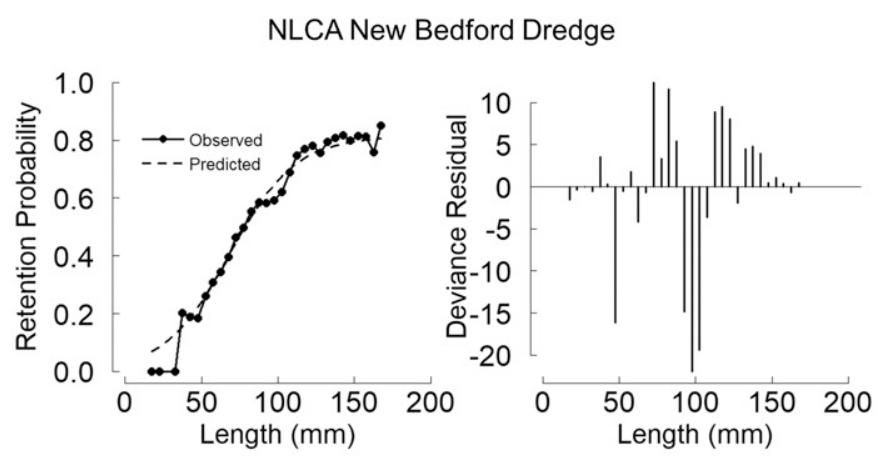

\section{CAll 2017 New Bedford Dredge}

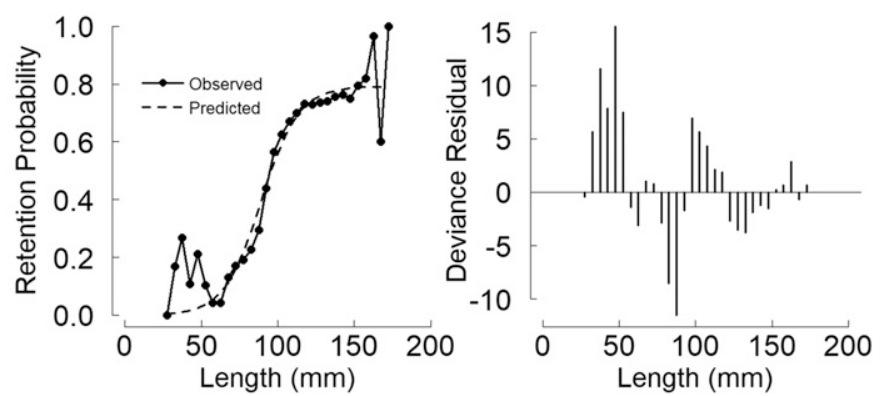

Georges Bank New Bedford Dredge

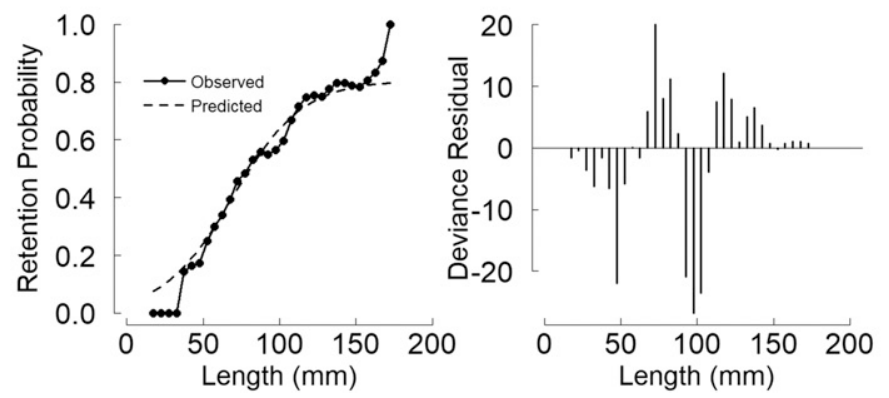

Figure 3. Predicted and observed proportion caught-at-length in the commercial gears (left) and deviance residual plots (right) for the logistic SELECT models for the Mid-Atlantic survey and the Coonamessett Farm Turtle Deflector Dredge (turtle dredge), the NLCA survey with the New Bedford dredge, the CAII 2016 survey with the New Bedford dredge, the CAII 2017 survey with the New Bedford dredge, and the New Bedford dredge on Georges Bank.

same time period when turtle dredge usage in the region was greatest.

The New Bedford dredge results suggest a shift in the selectivity of this gear since 2008 (Yochum \& DuPaul 2008). Both the $S R$ and $l_{50}$ values are greater and the dredge has an increased probability of retaining smaller scallops. The main driver behind this difference may be the size composition and density of the scallop population in the NLCA survey domain. In this area, there is a high-density bed of scallops in an area not presently fished by the commercial fleet (NEFSC 2018). These scallops have exhibited slow growth and yield, making them undesirable for harvest (NEFSC 2018). The size distribution is more variable and wider compared with other areas. The high catch volume may be compromising gear selectivity in this area during the time period the surveys in this study were conducted. Yochum and DuPaul (2008) found that catch volume of scallops increased the $S R$ but had no significant impact on $l_{50}$. This is consistent with results from this study. Other towed gear studies have reached similar conclusions regarding catch volume and reduced selectivity (Polet 2000, Herrmann 2005). As the catch volume increases over the course of a tow, the gear becomes clogged and mesh or rings are blocked by debris or organisms. This limits escapement of smaller animals through the gear, thus, increasing retention of smaller individuals (Polet 2000, Herrmann 2005).

Another high-density bed of scallops is located in the MidAtlantic region and may similarly impact the selectivity of the turtle dredge. This high-density bed also exhibited slower growth during the time period when the surveys in this study were conducted, but the size distribution was narrower than that observed in the NLCA survey area (NEFSC 2018). Although selectivity may have been comprised in the Mid-Atlantic region as a result of high scallop catches, the $S R$ and $l_{50}$ estimates for the turtle dredge do not show a similar pattern to the estimates for the New Bedford dredge (i.e., larger $S R$ and $l_{50}$ ). By contrast, the $S R$ is narrow and similar to the Yochum and DuPaul (2008) estimate and the $l_{50}$ is smaller. These results show parameter estimates for this dredge are robust to varying resource conditions. The results also indicate density is not a driving factor in the difference in $l_{50}$ estimates between the turtle 


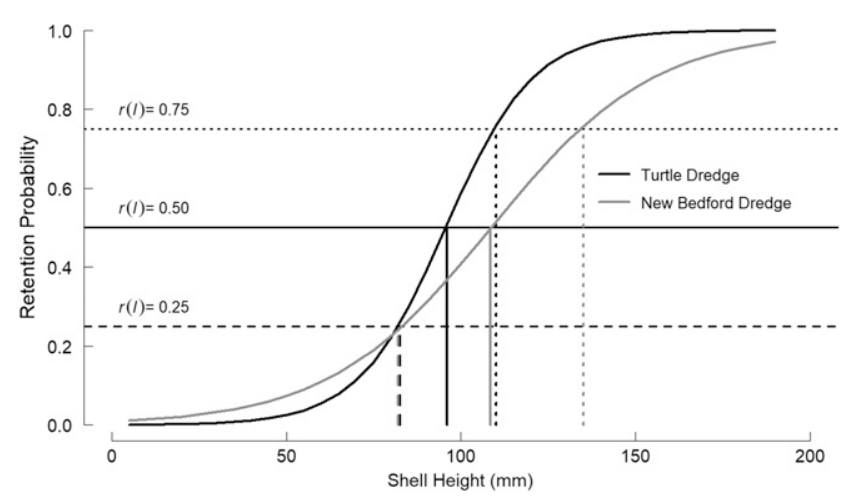

Figure 4. Predicted logistic selectivity curves for the Coonamessett Farm Turtle Deflector Dredge (turtle dredge, black line) and the New Bedford dredge (gray line) in this study. The lengths at 25th percent, 50th percent, and 75th percent probability of retention are shown for selectivity curves for both gears. Turtle dredge retention probabilities are black vertical lines and New Bedford dredge retention probabilities are gray vertical lines.

dredge and the New Bedford dredge. The $l_{50}$ estimates for the individual New Bedford dredge results are greater than the turtle dredge $l_{50}$ estimate, and the two CAII results are significantly different. Whereas the NLCA estimate is not significantly different, the mean $l_{50}$ value is greater and the variability around the estimate is related to the size composition of scallops in NLCA area, which has a broader distribution.

Differences between the New Bedford dredge results from this study and the 2008 findings provide evidence for timevarying selectivity for this gear. The last assessment used two fishery selectivity time periods of 1998 to 2017 and 2005 to 2017 for two areas on Georges Bank (NEFSC 2018). It may be appropriate to divide the last time period into smaller time blocks in future assessments to be more representative of the current resource conditions and gear selectivity. There also appears to be a difference in selectivity between the NLCA and CAII areas on Georges Bank, although no significant difference in parameter estimates for the two areas was detected. The NLCA survey has a larger $S R$ and a high probability of retaining smaller scallops, whereas the CAII results indicate $l_{50}$ is greater

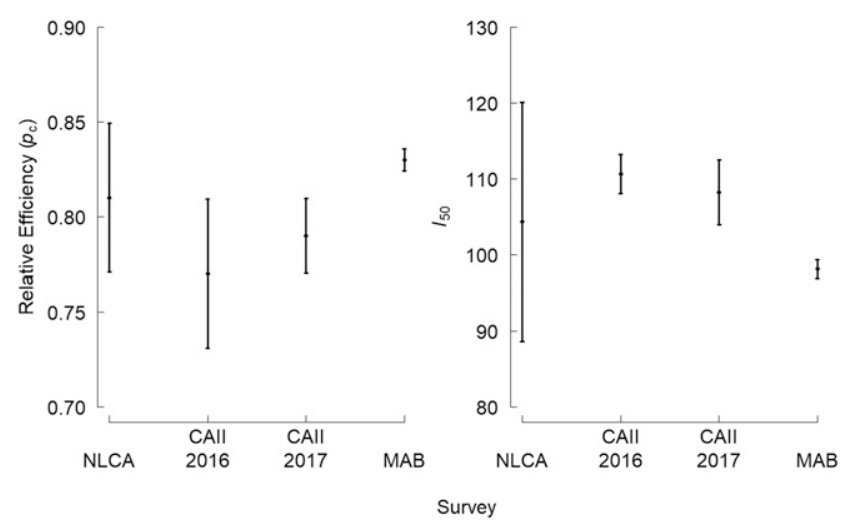

Figure 5. Estimates of relative efficiency $\left(p_{c}\right)$ and $l_{50}$ (50th percent retention probability) with $\mathbf{9 5 \%}$ CI for each survey in this study. NLCA is the Nantucket Lightship survey, CAII 2016 is the 2016 Closed Area II survey, CAII 2017 is the 2017 Closed Area II survey, and MAB is the MidAtlantic Bight survey.

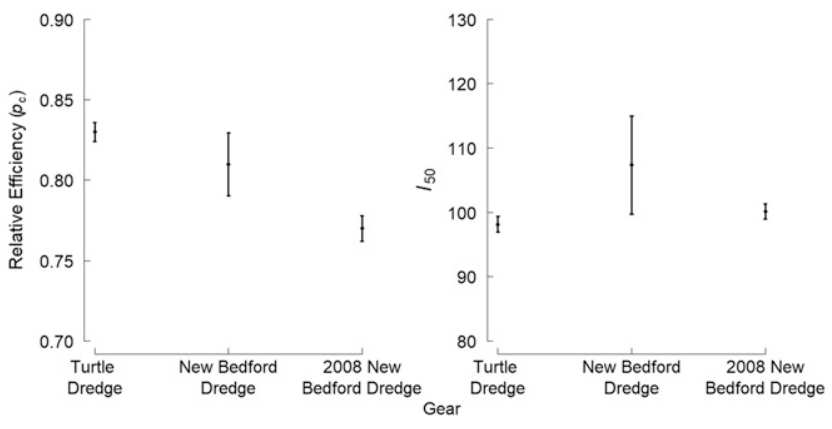

Figure 6. Estimates of relative efficiency $\left(p_{c}\right)$ and $l_{50}$ (50th percent retention probability) with $95 \%$ CI for each commercial gear type. The turtle dredge is the Coonamessett Farm Turtle Deflector Dredge, the New Bedford Dredge is the pooled New Bedford dredge results from this study, and 2008 New Bedford Dredge is the Yochum and DuPaul 2008 estimate.

in this area. The central driver behind this difference can be attributed to the high-density bed of scallops, the size distribution of scallops in the high-density area, and the patchy distribution of scallops in the NLCA survey domain. The highdensity bed of scallops may be reducing selectivity at high catch rates and in conjunction with the wide range of smaller scallops in the area is contributing to the larger $S R$. The patchy distribution is also contributing to increased variability in selectivity estimates as can be seen by the larger SE and REP factor. The NLCA REP factor of 49.97 is greater than the remaining REP factors by almost a factor of three. Although Yochum and DuPaul (2008) findings agree with results from this study to support combining both areas to estimate one selectivity curve for Georges Bank is appropriate and robust to varying resource conditions, it may also be suitable to evaluate spatially explicit fishery selectivity in the future, if high-density aggregations of scallops persist in the resource. Assessment of the selective profile of the New Bedford dredge across the resource should continue in the future to evaluate changes in selectivity as a function of time, resource conditions, and fishery practices.

Estimated relative efficiency values for both commercial gears are larger than the assumed relative efficiency values compared with the NMFS survey dredge based on gear width. The New Bedford dredge relative efficiency has also increased over time. These findings are similar to Yochum and DuPaul (2008), where New Bedford dredge relative efficiency was estimated at 0.77 compared with an assumed value of 0.65 . Both sets of results confirm the commercial dredges continue to be more efficient than expectation, although dredge width does not increase relative efficiency. The theory behind this difference is the use of the liner in the survey dredge decreases catch rates, although the causal mechanism for this remains unclear (Serchuk \& Smolowitz 1980, Yochum \& DuPaul 2008). Continuing to estimate the relative efficiency of commercial dredges to the survey dredge helps to provide a better understanding of how to interpret survey results in relation to potential fishery performance.

The difference in the selective profile between the turtle dredge and New Bedford dredge in this study may result from a combination of commercial fishing operations, fishing gear characteristics, and sea scallop swimming ability. Anecdotal information from commercial fishers indicate the turtle dredge is towed at a faster speed, an average of $10.1 \mathrm{kph}$, than 
the New Bedford dredge, with an average speed of $9.2 \mathrm{kph}$. Additional information from commercial fishers specifies the scope to depth ratio for the turtle dredge is also greater than that for the New Bedford dredge, which can allow the turtle dredge to maintain more consistent bottom contact. The modifications to the turtle dredge frame also changed the hydrodynamic flow for the dredge (Smolowitz et al. 2012a). Scallops exhibit avoidance behavior in relation to disturbances from fishing gear, and there is a relationship between avoidance behavior and size, where scallops smaller than $100 \mathrm{~mm}$ react to fishing gear at a higher frequency than larger scallops (Caddy 1968). The dredge towing speed may be too fast, thus not providing sufficient time for small scallops to escape (Jenkins \& Brand 2001). The hydrodynamics of the dredge may also limit escapement of smaller scallops after entering the dredge.

This study provides accurate and robust selectivity curves and parameter estimates for the turtle dredge, as well as updated estimates for the New Bedford dredge. Having accurate and updated information for both commercial dredges will assist fishery managers and assessment scientists in the future, especially as the use of the turtle dredge continues to grow in the commercial fleet. The New Bedford dredge selectivity analysis can provide insight into how the resource and commercial fleet will be impacted by regulatory changes, resource conditions, technology shift, and gear development.

\section{ACKNOWLEDGMENTS}

This study was funded through the NOAA Northeast Fisheries Science Center Sea Scallop Research Set-Aside Program Grant No. NA15NMF4540061, Grant No. NA16NMF4540041, and Grant No. NA17NMF4540029. The authors thank the commercial fishing vessel captains and crew, as well as the scientific staff from the Virginia Institute of Marine Science for participating in the surveys. The authors also thank Benjamin Galuardi from the Greater Atlantic Regional Fisheries Office of National Oceanic and Atmospheric Administration for providing commercial scallop dredge usage data for inclusion in the manuscript and Chris Rillahan from the University of Massachusetts Dartmouth, School for Marine Science and Technology, for his thoughtful and helpful review of the manuscript.

\section{LITERATURE CITED}

Caddy, J. 1968. Underwater observations on scallop (Placopecten magellanicus) behavior and drag efficiency. J. Fish. Res. Board Can. 25:2123-2141.

Cadrin, S. X., G. R. DeCelles \& D. Reid. 2016. Informing fishery assessment and management with field observations of selectivity and efficiency. Fish. Res. 184:9-17.

DuPaul, W. D. \& J. E. Kirkley. 1995. Evaluation of sea scallop dredge ring size. Contract report submitted to NOAA, National Marine Fisheries Service. Grant \# NA36FD0131.

Herrmann, B. 2005. Effect of catch size and shape on the selectivity of diamond mesh cod-ends II. Theoretical study of haddock selection. Fish. Res. 71:15-26.

Jenkins, S. R. \& A. Brand. 2001. The effect of dredge capture on the escape response of the great scallop, Pecten maximus (L.): implications for the survival of undersized discards. J. Exp. Mar. Biol. Ecol. 266:33-50.

Kvamme, C. \& K. Frøysa. 2004. Assessing the effects on stocks of selectivity changes in a fishery. Fish. Res. 2004:283-292.

Linton, B. \& J. R. Bence. 2011. Catch-at-age assessment in the face of time-varying selectivity. ICES J. Mar. Sci. 68:611-625.

Millar, R. B. 1992. Estimating the size-selectivity of fishing gear by conditioning on the total catch. J. Am. Stat. Assoc. 87:962-968.

Millar, R. B. \& R. J. Fryer. 1999. Estimating the size-selection curves of towed gears, traps, nets and hooks. Rev. Fish Biol. Fish. 9:89-116.

Millar, R. B., M. K. Broadhurst \& W. G. Macbeth. 2004. Modelling between-haul variability in the size selectivity of trawls. Fish. Res. 67:171-181.

New England Fisheries Management Council (NEFMC). 2003. Final amendment 10 to the scallop fishery management plan with a supplemental environmental impact statement, regulatory impact review, and regulatory flexibility analysis. Newburyport, MA: New England Fisheries Management Council.

New England Fisheries Management Council (NEFMC). 2011. Final framework 23 to the scallop fishery management plan. Newburyport, MA: New England Fisheries Management Council.

New England Fisheries Management Council (NEFMC). 2018. Final framework 29 to the scallop fishery management plan. Newburyport, MA: New England Fisheries Management Council.

Nielsen, A. \& C. W. Berg. 2014. Estimation of time-varying selectivity in stock assessments using state-space models. Fish. Res. 158:96-101.
Northeast Fisheries Science Center (NEFSC). 2018. 65th Northeast Regional Stock Assessment Workshop (65th SAW) Assessment Summary Report. US Dept Commer, Northeast Fish Sci Cent Ref Doc. 18-11. 659 pp. Available at: http://nefsc.noaa.gov/ publications/.

Polet, H. 2000. Codend and whole trawl selectivity of a shrimp beam trawl used in the North Sea. Fish. Res. 48:167-183.

R Core Team. 2016. R: a language and environment for statistical computing. Vienna, Austria: R Foundation for Statistical Computing. Available at: https://www.R-project.org/.

Revill, A. \& R. Holst. 2004. Reducing discards of North Sea brown shrimp (C. crangon) by trawl modifications. Fish. Res. 68:113-122.

Serchuk, F. M. \& R. Smolowitz. 1980. Size selection of sea scallops by an offshore scallop survey dredge. International Council for the Exploration of the Sea. ICES Counc. Meet Pap. 1980/K:24. Shellfish Division.

Smith, B. J., B. G. Blackwell, M. R. Wuellner, B. D. Graeb \& D. W. Willis. 2017. Contact selectivity for four fish species sampled with North American standard gill nets. N. Am. J. Fish. Manag. 37: 149-161.

Smolowitz, R., H. O. Milliken \& M. Weeks. 2012a. Design, evolution and assessment of a sea turtle deflector dredge for the U.S. Northwest Atlantic sea scallop fishery: impacts on fish bycatch. N. Am. J. Fish. Manag. 32:65-76.

Smolowitz, R., K. Goetting \& B. Valenti. 2012b. Testing of modifications to the Cfarm turtle deflector dredge for bycatch reduction: Final Report NA10NMF450473. Available at: https://www.nefsc. noaa.gov/coopresearch/pdfs/FR-10-0473_Testing_CFF.pdf.

Stepputtis, D., J. Santos, B. Herrmann \& B. Mieske. 2016. Broadening the horizon of size selectivity in trawl gears. Fish. Res. 184:18-25.

Park, H. H., R. B. Millar, H. C. An \& H. Y. Kim. 2007. Size selectivity of drum-net traps for whelk (Buccinum opisoplectum dall) in the Korean coastal waters of the East Sea. Fish. Res. 86:113-119.

Park, H., R. B. Millar, B. Bae, H. An, Y. Y. Chun, J. H. Yang \& S. C. Yoon. 2011. Size selectivity of Korean flounder (Glyptocephalus stelleri) by gillnets and trammel nets using an extension of SELECT for experiments with differing mesh sizes. Fish. Res. 107:196-200.

Yochum, N. \& W. D. DuPaul. 2008. Size selectivity of the northwest Atlantic sea scallop (Placopecten magellanicus) dredge. J. Shellfish Res. 27:265-271. 